\title{
The Applicability Scope of (L1) in The Teaching-Learning of The Skills, Sub-skills and Components of (L2): The role of (L1)-translation as A Vehicle Technique to Carry Out such A Scope
}

\author{
Abd-AL-Hameed Mustafa Mahmoud Jabsheh \\ Lecturer, Department of Languages, Palestine Technical University-Kadoorie (PTUK), Tulkarm Campus, Palestine \\ Corresponding Author: Abd-AL-Hameed Mustafa Mahmoud Jabsheh, E-mail: ptc2004w@hotmail.com
}

\section{ARTICLE INFORMATION ABSTRACT}

Received: December 08, 2020

Accepted: January 19, 2021

Volume: 4

Issue: 1

DOI: $10.32996 /$ ijllt.2021.4.1.15

\section{KEYWORDS}

L1, L2, Applicability Scope, English, L1-translation, Linguistic system, Skills, sub-skills
The aim of this study was twofold: First, I will identify the domains of the applicability scope of (L1) in the teaching-learning of skills, sub-skills and components of (L2). Second, I will find out the technique employed to carry out such an applicability scope of (L1) in the teaching-learning of skills, sub-skills and components of (L2). To achieve the purpose of this study, the researcher followed an argumentative analytical methodology while digging throughout the available related literature that was presented and arranged into a relative chronological format. Findings of this study indicate that those skills, sub-skills and components of (L2), which can be taught or learnt within such an applicability scope of (L1), are surprisingly very limited and not as wide as they thought to be because they constitute only (6) out of the sum of (37) other applications of this applicability scope which were categorized into two other domains of the (L1) applicability scope: the first constitutes (11) domains that are indirectly related to the teaching -learning of skills, sub-skills and components of (L2), and the second domain represents the sum of (20) other applications that are remotely and barely connected with the teaching -learning of skills, sub-skills and components of (L2). Findings of this study also indicate that (L1)-translation technique is the central, if not the lone, vehicle to be enhanced in order to implement such an applicability scope of (L1) in the teaching -learning of skills, sub-skills and components of (L2); in addition, this study concluded that (L1)-translation is practically enhanced as a method of assessment and testing to evaluate students or learners' achievement in (L2). As a result, this study came out with various related recommendations.

\section{Introduction}

Yang (2010, p. 77) explained that "L1 refers to one's mother tongue or native language, and L2 is any language excluding mother tongue." He also added that "L2 consists of a language basis, which differs from target language in terms of syntax, phonetics, semantics, and rhetoric. "These linguistic geographies, existing within (L1) and (L2), though they are predominately different as stated by some of the available related literature, do entail some similarities and some kind of a connective line, in the sense that students or learners normally begin their learning of (L2) from a native (L1)- threshold; as a result, some related research argues that this fact can be an advantageous and exploitable source, rather than a hindering or a blocking source on which to base the process of teaching - learning of (L2); in addition, some of the previous research proposed that students or learners of (L2) analogously follow an approximate and nearly close procedure to that which they had been following when they acquired their native (L1).

Some of the previous related literature further explained that if this built-in linguistic system of the native language (L1) is dealt with in an appropriate, orchestrated, and calculated methodology, it may facilitate and, to some extent, accelerate the process of learning and acquiring of (L2);moreover, some other related research argued that the use of (L1) in the teaching and learning of (L2) constitutes a phenomenon that is inevitable and unavoidable because (L1), in general, can represent a valuable and an

K C AL-KINDI CENTER R D FOR RESEARCH AND DEVELOPMENT Your gateway to world-class research

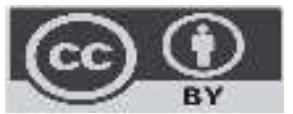

Published by Al-Kindi Center for Research and Development. Copyright (c) the author(s). This open access article is distributed under a Creative Commons Attribution (CC-BY) 4.0 license 
exploitable resource which may help in lowering the affective filters of the students, especially beginners, and may coordinate the effects of the socio-cultural factors and domains; in addition, some teachers with low proficiency levels in (L2), as acknowledged by previous research, enhance a usage of the native (L1) as a compensating tactic to bridge this proficiency gap, and, may be, in addition, to abide by the socio-linguistic demands and preferences of their students as well; enhancing the usage of the native (L1) in the teaching-learning of (L2) as a compensating methodology is normally sought because it is proposed to act as a spark to ignite students' socio-linguistic and affective platforms, a gap-filling and an offsetting mechanism to go with the demands of (L2) learning, a motivational move to encourage reluctant and low-proficiency students and learners, and also as a comforting policy to create a calm and disciplined classroom atmosphere that can facilitate a presumed rapid and more effective learning process of (L2) .

Finding a room for the use of (L1) in the teaching-learning of (L2), depending on the abovementioned justifying and adhering argument, has overlooked some important considerations and setbacks. First, switching to the use of (L1) by most teachers is dictated by various elements and circumstances like keeping up with students' preferences and needs, psycholinguistic and sociolinguistic factors, cognitive factors, students' attitudes and expectations, the demand of creating a relaxed classroom atmosphere, and the humble (L2) proficiency of some teachers, the proficiency levels of the (L2) students and learners, the learning-teaching context and environment, as well as the differences in the linguistic systems of (L1) and (L2), the whole teaching- learning atmosphere, and the cultural and affective boundaries of both (L1) and (L2). Second, this encouraging invitation to use (L1), in the teaching -learning of (L2), is general built upon the presupposition, as the findings of this study indicate, that (L2) is acquired or learnt nearly within the same procedure and mechanism which had been followed while acquiring (L1), which may not be accurate and lacks much empirical evidence because there are some major differences between the linguistic systems of both (L1) and (L2); third, this use of (L1) can have a damaging impact on the (L2) input an exposure in the form of yielding a distorted and non-authentic (L2) structures and patterns; fourth, and as stated by previous research, some teachers of (L2), exhibit an extent of contradiction between their real attitudes and the practices they perform inside classrooms while teaching the skills, sub-skills, and components of (L2).

To lower such negative impacts of the above mentioned considerations and to cope with the collateral problems and sideeffects, previous research recommends that it is very essential that the use of (L1) in the teaching-learning of (L2) should be enhanced reasonably, when necessary, appropriately, limitedly, and in a carefully calculated endeavor which can maximize the use of (L2) as much as possible, motivating students learning autonomy, and guarantees the authenticity of (L2) input, and which can enable students or learners to relatively produce authentic structures and patterns of (L2); in addition, this study proposes that there is a sole need to establish a defined and categorized referential scope of those skills, sub-skills, components of (L2) that may be dependent on the use of (L1) to be learnt or, to some extent, acquired; by the same token, this study proposes that it is also essential to define and categorize most of the teaching-learning practices that can be covered throughout this applicability scope of (L1) ; moreover, and within the research magnitude of this study, it is also critical to define the vehicle technique which is practically employed to carry out such an applicability scope of (L1) in the process of teaching-learning of the skills, sub -skills, and components of (L2).

As a result, and while (L2) is mostly viewed as to be English in either a second or a foreign setting, the aim of this study was to answer the following questions: 1. What are the domains of the applicability scope of (L1) in the teaching -learning of kills, subskills and components of (L2)? 2. What is the vehicle technique employed to carry out such an applicability scope of (L1) in the teaching -learning of skills, sub-skills and components of (L2)? To achieve the purpose of this study and to approach its questions, the researcher followed an argumentative analytical methodology digging throughout the available related literature which was molded into a relative chronological format.

\section{Statement of the Problem}

Some of the previous studies proposed that there is enough space for the native (L1) in the teaching-learning of (L2) depending on some justifying reasons and contexts, but the problem with this encouraging reasoning which supports the use of (L1) in the teaching-learning of (L2) is that : first, it overlooks some of the considerations, problems and negative side-effects that may arise while enhancing such a usage of (L1); and, second, it also overpasses the reasons why such problems and negative sideeffects occur ; as a result, this study proposes that these problems and those negative side-effects are a direct yield of the absence of any defined, categorized, and a tabulated applicability scope of (L1), but, instead, using (L1) in the teaching -learning of (L2) in an arbitrary approach which lacks a formidable reference. This study also categorized what has been randomly approached by previous research mainly the skills, sub-skills, and components of (L2) that directly depend on a defined applicability scope of (L1), and, also the vehicle technique through which such an applicability scope of (L1) can be implemented and carried out in the teaching-learning of those skills, sub-skills and components of (L2). 


\section{The significance of this study}

Achieving the goal of this study and approaching its questions entails a theoretical and a practical significance because of the fact that defining the boundaries of the applicability scope of (L1) in the teaching-learning of (L2) can lessen the negative sideeffects and the collateral problems that may arise as a result of such a use of (L1); this defined applicability scope of (L1) can also act as a reference which details all the skills, sub-skills, and components of (L2) that are dependent on a degree of enhancing a usage of (L1). Moreover, the significance of this study also emerges from the fact that it is the first study, as far as the researcher knows, to tabulate nearly a comprehensive applicability scope of (L1) which was randomly approached within the corpus of the available related literature; and, on the other hand, it is the first study, as far as the researcher also knows, to acknowledge the essentiality and centrality of (L1)-translation as a vehicle technique to carry out or implement the applicability scope of (L1) in the teaching -learning of the skills, sub-skills, and components of (L2), and, in addition, as a means of assessment and testing of (L2) proficiency and achievement. As a result, and in accordance with the significance of this study, this tabulated and strictly classified format -of the skills, sub-skills, and components of (L2), as well as, the (L1)-based vehicle technique through which these can be implemented or carried out can provide teachers, educators, and curriculum planers with a stronger and a pertinent consideration while exploiting the applicability scope of (L1) in the teaching -learning of the skills, sub-skills, and components of (L2).

\section{Literature review}

The aim of this literature review, which was moored to the purpose and questions of this study, is to justifiably enrich the main argument and proposal of this study. As a result this review is divided into four sections: The first section presents the rational and justification supporting the use of (L1) in the teaching-learning of (L2); the second section of this literature review details the applicability scope of (L1) in relation to the teaching-learning of the skills, sub-skills, and components of (L2); the third section considers the role of (L1)-translation throughout the whole process of the teaching-learning of the skills, sub-skills and components of (L2); while the fourth section presents an account of the collateral problems and side-effects that may occur while carrying out such an applicability scope of (L1).

\subsection{Rationale and justification supporting the use (L1) in the teaching-learning of (L2):}

The following section of the available related literature presents an overview of some considerations that support and, at the same time justify the use of (L1) in the teaching - learning of (L2) which is mostly viewed as to be English throughout this review:

Atkinson (as Cited in Mart, 2013, p. 9) concluded that "although the mother tongue is not a suitable basis for a methodology, it has, at all levels, a variety of roles to play which are at present consistently undervalued". Mart (2013, p. 10 ) argued that it is impossible to keep L1 and L2 apart and concludes that: "the L1-L2 connection is an undisputable fact of life, whether we like it or not the new knowledge is learnt on the basis of the previously acquired language. SchweersJr p. 6) stated that "Starting with the L1 provides a sense of security and validates the learners' lived experiences, allowing them to express themselves. The learner is then willing to experiment and take risks with English. Mart (2013, p. 10) concludes that "use English where possible and L1 where necessary. Alrabah, Alotaibi and Aldaihani $(2016$, p. 3) argued that there were pedagogical as well as affective factors contribu ting to L1 use in the L2 classroom." SchweersJrn (1999, p. 13) also concludes that "a second language can be learned through raising awareness to the similarities and differences between the L1 and the L2. The prudent use of L2 in the English classroom also affirms the value of our students' L1 as their primary means of communication and cultural expression." Gomathi and Kiruthika (2013, p. 24) stated that "Steven Krashen, with his Natural Approach to language acquisition, proposed that students learn their second language much in the same way that they learn their first, and that L2 is best learned through massive amounts of exposure to the language with limited time spent using L1." Turnbull, Arnett and Ausubel (as cited in Ghobadi, \& Ghasemi, 2015, p. 246 ) proposed that " the process of second language teaching should work on what learners already know about the nature of language knowledge." Nation $(2003$, p. 7$)$ found that "In some countries, English and the L1 are in competition with each other and the use of English increases at the expense of the L1. Teachers need to show respect for the learners' L1 and need to avoid doing things that make the L1 seem inferior to English. At the same time, it is the English teacher's job to help learners develop their proficiency in English. Thus, a balanced approach is needed which sees a role for the L1 but also recognizes the importance of maximizing L2 use in the classroom." Ghobadi and Ghasemi (2015, p. 249 ) found that "the students also resorted to their L1 even for non-compensatory purposes." Giles and Ogay (as cited in Alrabah, , Wu, Alotaibi, \& Aldaihani, 2016 p. 4) concluded that "When the teacher accommodates the students' sense of national, linguistic and cultural identity by using the students' $L 1$, he/she can increase rapport with students which may facilitate the L2 acquisition process. Moreover, teachers' L1 use can be seen as a form of convergence to the students' speech patterns." Farrah, and Salah (2012 p. 401) proposed that "a positive contribution to English learning can be fulfilled through teaching English bilingually if L1 is used at appropriate times and for appropriate reasons. Debreli (2016, p. 25) States that "students are often unresponsive, inattentive, and unwilling to speak in class" (p. 692), but when L1 is used the opposite are true". Al-Jadidi, 2009,p. 41) concluded that "some Arabic- speaking bilinguals and Omani local teachers may not have enough fluency to be able to 
conduct their classes wholly or mainly in English". De la Campa and Nassaji (as Cited in Alrabah, Alotaibi \& Aldaihani, 2016 p. 3) found that "Experienced EFL teachers, it seems, have an intuitive feel about their students' proficiency levels and they adjust their L2 input accordingly to accommodate students including the use of L1 in L2 teaching." Alrabah, Alotaibi and Aldaihani (2016 p. 4) concluded that "the two instructors switched to $L 1$ to accommodate their learners' lack of proficiency in the $L 2$. This process can be interpreted as convergence to students' speech patterns in the social setting of the classroom." Ghobadi and Ghasemi (2015 p.251) suggested that " L1 be optimally used in language classrooms. By optimal L1 use, Macaro, means L1 use that "can enhance second language acquisition and/or proficiency better than second language exclusivity". Debreli (2016 p. 25), found that "type of textbook and parental concerns pushed teachers to use L1 and help students achieve better results in their examinations." Farrah and Salah (2012. p. 401) concluded that "it is believed that teaching English monolingually will increase the learning of the language, regardless of whatever other languages the learner may know." Kayaoğlu, (as cited in Debreli,2016, p. 30) found "that teachers preferred not use L1 with higher levels students, but were inclined to use it at beginner levels. In his study, the teachers' main concern was found to be regarding time saving, that is, the teachers also preferred L1 use when they had time constraints while teaching a topic; and without any differentiation between the levels of the students, they chose to use L1 when they needed to save time". Mart (2013, p. 9) concluded that "It has been widely advocated that insistence on Englishonly policy and the complete prohibition of L1 would maximize the effect of learning L2 but recent studies demonstrate that the appropriate use of L1 has a facilitating role in L2 classroom".

Rabbidge (as cited in Alrabah, Alotaibi, \& Aldaihani, 2016, p.9 ) stated that "in many EFL classrooms from different language backgrounds, teachers used L1 for more than $40 \%$ of actual class speaking time. He concluded that several research studies in EFL settings have, however, revealed that when teachers of English share the same first language (L1) background with their students, they use L1 alongside the second language (L2) to teach English". Ghobadi and Ghasemi (2015, pp, 246-247) argued that "According to the theory, bilinguals enjoy a shared conceptual store for L1 and L2 lexicons that is characterized by an increasing number of semantic connections that are not language-specific until they are required to be so based on the context of language use. The argument goes that, at elementary levels of $L 2$ acquisition, it is better that language teachers and learners invest in those semantic connections that are more L1-based. They proposed that "there are a number of challenges and obstacles for the use of L1 and L1-based techniques in L2 classrooms that need to be addressed. The most obvious obstacle for using the L1-based techniques in language classrooms is that it is only appropriate when all learners in the classroom possess the same mother tongue. Therefore, monolingual approaches that only make use of the target language in classrooms are more appropriate for such contexts. Further, even if L1 use is justified in L2 classrooms, teachers should take care of learner autonomy when letting their students make use of their mother tongue. Learners should not be driven to think that L1 can substitute the L2 whenever they encounter L2 communication problems. Ghobadi and Ghasemi (2015, p. 252) also recommended that " judicious L1 use in classrooms provide learners with cognitive advantages for acquiring the L2. As a matter of fact, many empirical studies on the issue have supported the idea that judicious L1 use can facilitate the process of L2 acquisition.

Alrabah, Alotaibi and Aldaihani $(2016$, p. 7) stated that "on the one hand, some claim that minimizing L1 use will result in better and faster rates of L2 acquisition. On the other hand, others see a useful role for L1 as a teaching tool that can facilitate L2 acquisition. Probably, the teachers' responses reflect the controversy regarding L1 use in L2 teaching. They found that "the teachers believed the context of the L2 classroom had an effect on their using L1 to teach L2.". They added that " there were three items related to sociolinguistic factors. First, the teachers agreed that their having a language in common with their students was a reason why they used L1. Second, they agreed that students' use of L1 to address their teachers made them respond in the L1 as a form of convergence to adjust to the speech patterns of the students". They also concluded that "The issue of using L1 while teaching L2 represents a contradiction facing EFL teachers as they go about their daily task of teaching L2. On the one hand, teachers employ L1 for a variety of functions as a language teaching tool and for classroom management. On the other hand, they seem to have negative attitudes toward L1 use in L2 teaching". They stated that the results from these studies suggest that there is a relationship between students' low levels of proficiency and teachers' use of L1 in the language classroom. Debreli (2016 p. 29) proposed that "It is us [teachers] who are with the students all day long and it is only us who experience the bad sides of not being able to use L1 in our classrooms." He added that "students always insisted on the use of $\mathrm{L} 1$, and the teachers always had to refuse, which then lead to a fall in students' enthusiasm. The majority also believed that this is also reflected in students' performance, as they become unwilling to participate in class on subsequent occasions. He also recommended that "Although the duty of learners' learning English is to understand the input provided to them in English, I don't see it that way. I mean, when they reach a certain level, they should be given input in L2, but until they reach that level, we should guide them in L1 at certain points. Otherwise, they might learn things incorrectly. Sevim and Turhanli (2019, p. 863) reasoned that "Because L1 is a tool to respect learners' identity and related with both its psychological and socio-cultural roles." 
To sum up, the previous review supports using (L1) in the teaching -learning of (L2) because of various reasons and justifications : firstly, the previous review proposed that students and learners of (L2), which is mostly English all through this study, do not start the process of learning and acquiring of (L2) while they are empty-handed, but on the contrary, while they are standing on the threshold of the previously acquired (L1) native system; the existence of this connective line between the system of (L1) and that of (L2) obligates teachers of (L2) to, directly or indirectly, anchor the whole teaching-learning process of (L2) to that (L1) system, and, consequently, realize that it is impossible to keep (L1) a way while teaching and learning ( L2 ) because if (L1)is completely avoided or banished, various hindrances may decelerate the whole process of teaching-learning of (L2); secondly ,the previous review proposed that an appropriate use of (L1) may have a facilitating, enhancing, and advantageous impact on the teaching, learning, and acquiring of (L2) because such a usage of (L1) reflects some kind of harmony with students preferences, the psychological, and the socio-cultural dimensions of their native identity and linguistic habitat, which in turn , if respected, can establish a relaxed atmosphere and boost forward the whole process of (L2) learning; thirdly, the previous review considered the use of (L1), in this context, as a technique to minimize the amount of reluctance and a method of motivating unwilling students or learners in order to more participate in classroom activities, on the ground that those unwilling students or learners who may not strive if (L1) is not used, especially those with low proficiency levels in English; fourthly, another inviting rationale to use (L1) in the teaching-learning of (L2), as proposed by the previous review, is that students or learners of (L2) relatively follow the same techniques and procedures they had been following when they acquired their native (L1). Teachers, in accordance with the previous review, resort to use (L1) while teaching (L2) , which is mostly English as considered by the previous review and by this study, for various reasons: first, some teachers may not be able to conduct and orchestrate the whole process of teaching -learning process and environment while using only (L2) due to the fact that they are proposed to have low fluency levels in (L2); second, the previous review deems it to be an advantage that both students and teachers share the same (L1) because this may ignite students' socio-linguistic and affective platforms; third, the previous review concludes that teachers are normally aware of the fact that their students and learners resort to (L1), as an offsetting mechanism, to comprehend the demands of (L2) learning.

Regardless the fact that the previous review, foregrounded some reasons that seem to justify the use of (L1) in the teachinglearning of (L2), another fact emerges that the use of (L1) is predominately dictated by various elements and conditions such as pedagogical, affective, linguistic, students' level and proficiency in (L2). Also, the similarities and difference in the systems of (L1) and (L2), the context of (L2) classroom, and the attitudes and beliefs of teachers themselves towards such employment. As a result, the previous review recommends that (L1) should be employed reasonably, when necessary, appropriately, limitedly, and in a carefully calculated endeavor that can leave an enough space to maximize the amount of exposure to (L2) on the one hand, and to enable, as much as possible, students learning autonomy that can guarantee a rapid process of learning and acquiring of (L2).

4.2 The domains of the Applicability Scope of (L1) in the teaching-learning of the skills, sub-skills, and components of (L2):

In this section of the literature review, the researcher has investigated in a survey-like methodology an adequate number of the available related studies in order to tabulate the domains of the applicability scope of (L1) in the teaching-learning of the skills, sub-skills and components of (L2); these domains categorizes nearly all the practices, circumstances and conditions where (L1) is used in this related context:

Alrabah, Alotaibi and Al-Deehani (2016, p .8) suggested that L1 can be used to perform a variety of functions in the language classroom, such as checking for comprehension, giving instructions and explaining lexical items and grammatical concepts." Schweers $(1999$, p. 6) suggested the following possible occasions for using the mother tongue: negotiation of the syllabus and the lesson; record keeping; classroom management; scene setting; language analysis; presentation of rules governing grammar, phonology, morphology, and spelling; discussion of cross-cultural issues; instructions or prompts; explanation of errors; and assessment of comprehension." Ghobadi and Ghasemi $(2015$, p. 247) concluded that "several of the managerial functions that L1 use can serve in language classrooms are as the following; giving assignments, creating a friendly classroom atmosphere, providing feedback, managing classroom discipline, and building rapport between the teacher and the leaner". Knight (as Cited in Nation, 2003, p. 3), found that " learners who did the preparatory L1 discussion in groups did much better on the L2 written task than other learners who did preparatory L2 discussion even though that discussion was in the same language as the subsequent written task". Farrah and Salah $(2012$, p. 401) proposed that "L1 is justified to be used for different reason, e.g. it can be used to introduce the major differences between the L1 and the $L 2$, to save a lot of guessing, to motivate students and to reduce their anxiety. They found that "there is a considerable amount of literature which strongly suggests that the mother tongue can play a supportive and facilitating role in the EFL classroom as a valuable linguistic resource, and consequently, it should not be totally avoided.("Tang, as Cited in Mart, 2013, p.10), "identifies the uses for L1: classroom management, language analysis, presenting rules that govern grammar, discussing cross cultural issues, giving instructions or prompts, and checking for comprehension". Meyer (as Cited in Alrabah, Alotaibi, \& Aldaihani,2016, p.3) indicated that "the primary role of the students' L1 
in the language classroom is lowering affective filters" . He argued that for L2 input to be made comprehensible, L1 may be used by the teacher to ensure a low affective filter among the students, thereby facilitating L2 acquisition. Debreli (2016 p. 25) found that "teachers needed to use L1 when giving instructions and explaining new concepts. Al-Jadidi (2009, p. 155), concluded that " In grammar lessons, students expect me to explain in Arabic as other bilingual teachers do". He also added that "In summary, the purposes and functions for which the bilingual teachers used Arabic were stated as: • Explaining the rules of grammar and word meanings • Discussing cultural ideas • Giving immediate, comprehensible feedback - Pointing out differences between the structures of each language - Saving classroom time - Building motivation - Maintaining discipline. Ghobadi and Ghasemi (2015, p. 24) proposed that "This managerial function of $L 1$ use in language classroom has the positive role of helping the learners not become confused between what is important to the process of L2 acquisition (i.e., the instructional content) and what is deployed to facilitate this process (i.e., logistics aspects of the process of L2 teaching). So it is highly recommended that, particularly at elementary levels, these managerial functions be handled through L1 use so that learners are able to focus their attentional resources on what is to be learned. Alrabah, Alotaibi and Aldaihani $(2016$, p.3) found that L1 was used for translation, L1-L2 contrasts, evaluation (L1 utterance used to evaluate students' contributions), activity instruction, setting the activity objective, elicitation of student contributions, personal comments, comprehension checks, classroom management, administrative issues (e.g., exam announcements), repetition of students' utterances, reaction to students' questions in L1, humor, code-switching, code-mixing, and using L1 words from L1 culture. These results suggested that L1 can play a complementary role to the L2 especially in EFL contexts where the teacher shares the same L1 background with the students."

Debreli $(2016$, p. 30) concluded that "where the teachers were found to be differentiating the instances when L1 should be used in terms of the language skills (i.e., L1 had no role during writing, but was required when speaking), no sensitivity with regard to the use of L1 when teaching specific language skills were identified. He also found that L1 was required by non-native teachers for the purposes of clarification, checking comprehension and classroom socialization. Alrabah, Alotaibi and Aldaihani $(2016$, p.3) proposed several functions for using L1 in L2 teaching, such as conveying and checking the meanings of words and sentences, explaining grammar, organizing the class, organizing tasks, maintaining discipline, contact with individual students, and testing." They also proposed that "L1 could be used to check for comprehension, give instructions, organize tasks, maintain discipline, build rapport, and explain difficult lexical items and grammatical rules and concepts. Gomathi and Kiruthika (2013, p.26), proposed that " L1 helps to check understanding of very complex expressions, like idioms, phrases, etc". They concluded that " sometimes, L1 use in language classrooms is not a matter of choice, but is rather inevitable. For example, it would be really hard to manage language classrooms, particularly at elementary levels, without the help of learners' mother tongue. From this viewpoint, L1 use can serve many managerial functions. They also added that "providing L1 glosses for unknownwords in an L2 text would improve L2 learners' depths of comprehension of the text.". Alrabah, Alotaibi and Aldaihani (2016, p.3). argued that "During their attempts to simplify L2 input to adjust to learners' proficiency levels, teachers in EFL settings often use L1 to make themselves more comprehensible. Therefore, the language that teachers address to language learners is often simplified and the degree of simplification relates to the learners' levels of proficiency. They found that "teachers indicated that they employed the $\mathrm{L} 1 \mathrm{as}$ a teaching tool to explain the meanings of difficult words and concepts, compare the grammatical rules of the L2 to those from the L1. The teachers also used L1 to perform a number of classroom management functions including giving instructions during tests by using L1, maintaining discipline in class, and taking students' attendance". They added " that the teachers used L1 in $\mathrm{L} 2$ classrooms as a teaching tool and for classroom management". They also found that "affective factors that contributed to teachers' L1 use to create a more relaxed classroom environment."Frequently, the instances when L1 should be used in EFL classrooms were given as follows: when giving instructions, when explaining difficult topics, when defining vocabulary, and when socializing in the classroom.

Debreli (2016, p. 24) found that "many scholars have started to consider the advantages of $L 1$ and socializing in the classroom). speaking the same L1 as the students, and have been looking for ways to improve learning and teaching (i.e., explaining difficult concepts using. He added that "A popular idea emerging from the data indicated that the teachers preferred the use of L1 when defining difficult topics or when explaining complex grammatical tasks. He also concluded that "the main reason for teachers preferring the use of the L1 was related to the concern that the students may misunderstand the new vocabulary items or the input provided to them". Sevim and Turhanli (2019. P, 861) argued that teachers " believe that L1 should be used with lowproficiency level students when making students aware of the differences and similarities between L1 and L2,explaining new vocabulary, clarifying difficult concepts, solving disciplinary problems and teaching grammar."

To sum up, the previous review revealed that the applicability scope of using (L1) in the teaching-learning of (L2) extends to include three domains: the first one includes those practices that are directly connected with the teaching-learning of the skills, sub-skills, and components of (L2); the second one includes a category of those practices that are indirectly related to the teaching-learning of the skills, sub-skills, and components of (L2); while the third includes a category of circumstances that are 
remotely and barely related to the teaching-learning of the skills, sub-skills, and components of (L2). The previous review proposed that the use of (L1) in the teaching-learning of the skills, sub-skills, and components of (L2)could be a valuable resource that may help in lowering the affective filters of the students, especially (L2) beginner learners and students, and may also help in accelerating the process of (L2) learning as well. The applicability scope of (L1) in the teaching-learning of the skills, sub-skills, and components of (L2), and in accordance with the previous review, though it is considered to be an inevitable and justifiable move, but, at the same time, the role of which should be complementary, facilitative, and supportive as far as possible.

\section{3 (L1)-translation as a vehicle technique to carry out the applicability scope of (L2):}

The following review reflects the points of view in regard to the role of (L1)-translation in carrying out the applicability scope of (L1) in the teaching -learning of the skills, sub-skills, and components of (L2):

Atkinson (as cited in SchweersJr, 1999, pp, 6-7), "lists appropriate uses for the L1 in the L2 classroom Using translation to highlight a recently taught language item. Translation items can be useful in testing mastery of forms and meanings. (Atkinson, As Cited in ( Alrabah, Alotaibi, \& Aldaihani,2016, p.3). "for example, has listed appropriate uses for L1 in the L2 classroom that included eliciting language, using translation, and testing. Nation (2003, p. 4) concluded that" L1 translations are usually clear, short and familiar, qualities which are very important in effective definitions. Mart (2013, p. 10) "encouraged the use of L1 as it helps students with comprehension and communication effectively. Moreover, the use of translation provides students an opportunity to notice similarities and differences between L1 and L2. Ross (as Cited in Mart, 2013, p.10) stated that "Translation holds a special importance at an intermediate and advanced level: in the advanced or final stage of language teaching, translation from L1 to L2 and L2 to L1 is recognized as the fifth skill and the most important social skill since it promotes communication and understanding between strangers". He states that translation develops three qualities essential to all language learning: accuracy, clarity, and flexibility that will help students learn effectively. Nation $(2003$, p. 3) concluded that "There are numerous ways of conveying the meaning of an unknown word. These include a definition in the second language, a demonstration, a picture or a diagram, a real object, L2 context clues, or an L1 translation. De la Campa and Nassaji (as Cited in Alrabah, Alotaibi, \& Aldaihani,2016, p.3) found that L1 was used for translation. Taki, Soghady and Reza $(2013,824$ ) concluded that " the most favored strategy used by learners of different levels was translation. Translation to L1 (Persian) was also the mostfrequent strategy in decoding similar, identical and different types of idioms". Ghobadi and Ghasemi (2015, p. 247) confirmed that "Translation is by far the oldest L1 techniques used in language classrooms. In fact, as mentioned before, translation and bilingual word lists were the major L2 teaching and technique techniques till the early twentieth century". They also concluded that "three of the most important L1-teachniques which had attracted the most attention in the SLA field were chosen for the review. The three L1-teachniques chosen for review were translation, code switching, and L1 glossing."

To sum up, the previous review considered (L1)-translation to (L2) items, components, and patterns as to be a central (L1)related technique in the teaching-learning and testing of (L2) for various reasons: The first, (L1)-translation and bilingual wordlists were one of earliest used methods in the teaching-learning of (L2) vocabulary items as they are short, direct, and can quickly familiarize students and learners with the domain of meaning and definitions of a given(L2) item; second, the previous review proposed that (L1)- translation provides students and learners with an opportunity to notice, consciously or sub consciously, the similarities and differences between the linguistic systems of both (L1) and (L2); third, and as proposed by the previous review, (L1)-translation can be an effective method that help students learn effectively as it helps developing essential language-learning qualities such as accuracy, clarity, and flexibility; fourth, (L1)-translation, as stated by previous review, is viewed as the fifth skill which plays an important social role through promoting communication and understanding between strangers; the fifth reason is that (L1)-translation is used as a method of testing, evaluation, and assessment of (L2) learning and competency and achievement; in this regard, the researcher believes that further empirical and correlative research is needed in order to shed more light on the role of (L1)-translation as a means of assessment and testing of (L2) competency .

(L1)-translation to (L2) items, components, and patterns, as indirectly presented by the previous review, is considered as the most important, if not the lone, vehicle technique to be used in order to carry out the applicability scope of using (L1) in the teaching-learning of the skills, sub-skills and components of (L2); in this regard, the researcher also believes that further research is mostly needed to uncover this issue.

\subsection{Problems related to carrying out the applicability scope of (L1):}

Regardless the vouching argument presented by the above mentioned review of the available related research in regard to the use of (L1) in the teaching-learning of (L2), the following review presents a mitigating account overviewing some of problems and negative side-effects that are bounded up with enhancing (L1) in the process of teaching-learning of (L2):

Alrabah, Alotaibi and Aldaihani $(2016$, p.7) found that "results related to teachers' attitudes indicated that teachers' attitudes toward using L1 in teaching L2 were in opposition to their actual classroom practices". They added that "Teachers in foreign 
language contexts including Kuwait are often compelled to using the L1 when learner needs called for its use. They recommended that " there is a need to explore teachers' solutions to the problems inherent in students' less than ideal exposure to L2 input as a result of L1 use in L2 teaching" Atkinson and Weschler (as cited in Farrah, \&Salah, 2012, p. 405) stated that" It could be concluded that the principle in teaching English should be use English where possible and L1 where necessary. Ghobadi and Ghasemi (2015,p. 252), confirmed that "L1 use should not constrain the amount of L2 input learners are exposed to in the classroom." Wolter (2001,p. 41) elaborated that "Although researchers have historically been cautious in their attempts to devise any definitive model for the structure of the $\mathrm{L} 2$ mental lexicon, the results of L2 studies in this area have generally supported the notion that it is in many ways fundamentally different from that of the L1." SchweersJr (1999, p. 6) found that "Approximately 99 percent of the students responded that they like their teachers to use only English in the classroom. Copland and Neokleous (2011, p.6) stated that "decisions about when to use L1 and L2 are complex and seem to be based on both affective and cognitive factors". Copland and Neokleous (2011, p. 6) also elaborated that in terms of affective factors, teachers responded to their students' contributions, whatever language they used, in what seemed to be an effort to create a stress-free learning environment. Alrabah, Alotaibi and Aldaihani (2016, p.3 ) concluded that " teachers' decisions to switch from L2 to L1 within the context of the classroom can be motivated by a variety of affective, sociolinguistic, and psycholinguistic factors that may contribute to their L1 use in the L2 classroom." They concluded that "Learning a foreign language has been compared to L1 acquisition many times but there are some differences. They found that " there was a lot of interference of L1."(Ringbom, 1983, p. 10 ), concluded that "The smaller the perceived distance between the L1 and the L2, the more relevant this prior L1-knowledge is to the learner; especially at the early stages of learning." Ringbom (1983, p. 10 ), confirmed that"It is not only relevant whether $\mathrm{LI}$ and L2 actually differ or are the same at a particular point or not, but rather whether the learner expects or believes this to be the case: It is the learner's attitude and expectation that determines transfer or generalization within L2." He found that "A learner easily perceives cross-linguistic equivalence between phonological and morphological items, if the L2-items are formally similar to L1-items with approximately the same function and meaning."

To sum up, the previous review revealed some problems in the realm of using (L1) in the teaching-learning of (L2) : First, the previous review revealed a contradictory state of being between what teachers actually do in classrooms and their real attitudes towards the use of (L1) in the teaching-learning of (L2); second, the previous review found that, in most cases, switching to (L1) by most teachers is dictated by various elements and circumstances such as keeping up with students' affective repertoire , students' preferences and needs, psycholinguistic and sociolinguistic factors, cognitive factors, students' attitudes and expectations, and, in addition, the pressing demand of creating a relaxed classroom environment so that the teaching-learning process goes smoothly and in disciplined atmosphere; the third problem related to the use of (L1)in the teaching-learning of (L2), and as revealed by the previous review, is the proposed negative and the damaging impact of such a usage on the input and the amount of exposure to (L2),which should not be minimized by an excessive use of (L1) ; the fourth problem , which was presented by the previous review, is that the use of (L1) is usually built upon the presupposition that (L2) is acquired or learnt nearly within the same procedure that had been followed when (L1) was acquired, but this is proved to be not accurate, in reference to the previous review, due to some major differences in the linguistic systems of both (L1) and (L2); the fifth problem is that the previous review confirmed that nearly most students and learners prefer bilingual teachers who use (L1) while teaching (L2), which is mostly English in this regard. The previous review concludes that there is a need to find solutions to the negative side-effects resulted from the mentioned problems, especially that which is related to damaging the amount and quality of (L2) input and exposure, and the transfer of some aspects of (L1) linguistic system into that of (L2). The previous review also recommends that a strict balance should be sought while using (L1) in the teaching-learning of (L2).

\section{Discussion}

The aim of this study was to approach the following questions: 1 . What are the domains of the applicability scope of (L1) in the teaching -learning of the kills, sub-skills and components of (L2) ? 2. What is the vehicle technique employed to carry out such an applicability scope of (L1) in the teaching -learning ofthe skills, sub-skills and components of (L2)? To answer these questions, the researcher followed a qualitative analytical approach which was applied on the sum of the available related literature in an investigative and a survey-like procedure.

Investigating previous studies provided enough data that enabled the researcher to address the mentioned questions of this study and then drew related conclusion. In regard to the first question of this study, the amassed data made it possible for the researcher to build a tabulated, classified, categorized, and fully defined account of such an applicability scope of (L1) although the topic was presented throughout the available related literature in uncategorized and unclassified format, but, on the contrary, in a general, random, and mostly scattered consideration. 
Accordingly, and as shown by the table below, this study categorizes three domains that constitute the applicability scope of using (L1) in the teaching-learning of the skills, sub-skills, and components of (L2) : the first one includes a list of only (6) practices when (L1) is used to teach the skills, sub-skills, and components of (L2); the second includes a list of (11) practices which are indirectly related to the teaching- learning ofthe skills, sub-skills and components of (L2); while the third lists a category of (20) other practices when (L1) is used, but in a manner that is remotely and barely related to the skills, sub-skills and components of (L2). Surprisingly, the table below, and in accordance with the findings of this study, listed only (6) practices that are directly connected with the teaching-learning of the skills, sub-skills and components of (L2); these only (6) practices can be considered very few in comparison with the other (37) practices within the other two domains, but also indicative that the applicability scope of (L1) in the teaching-learning of (L2) is largely enhanced as an instrumental , organizational, and facilitative methodology that is either indirectly related to the skills, sub-skills and components of (L2) or remotely and barely related to those skills, sub-skills and components of (L2).The classification and tabulation of the domains of the applicability scope of (L1) in the teaching-learning of skills, sub-skills and components of (L2)are meant to give a referential insight into the boundaries of such a scope of (L1), and not as an open invitation to use the categorized practices excessively, as a rule thumb, within the teaching-learning of every skill, sub-skill, and component of (L2), and as a requisite for the process of teachinglearning of (L2). The classification and tabulation of the domains of the applicability scope of (L1) in the teaching-learning of skills, sub-skills and components of (L2) go with what has been proposed by some of the available related research that the use of (L1) in the teaching-learning of the skills, sub-skills and components of (L2) must be carefully calculated, instrumentally balanced, and reasonably approached, lest damaging the linguistic input and the amount of exposure to (L2).

As also revealed by the table below, the limited number of the skills, sub-skills, and components of (L2) that are supposedly dependent on (L1)to be taught or learnt mirrors and agreement with the argument posed by some of the available related literature that it may be not accurate to suppose that students or learners of (L2) analogously follow an approximate and nearly close procedure to that which they had been following when they acquired their native (L1); had the case been like that, the researcher believes, students or learners of (L2) would not have needed any applicability scope of (L1), but, on the contrary, the process of learning (L2) would have happened automatically, innately, and without needing much exposure or input of (L2).

Table (1): The domains of the applicability scope of (L1) in the teaching-learning of the skills, sub-skills and components of (L2).

\section{a. Practices that are directly related to language skills, sub-skills and components of (L2). \\ c. Practices that are remotely and barely and related to the teaching-learning of skills, sub- skills and components of (L2).}
1. Explaining lexical items and misunderstood new vocabulary.
2. Teaching-learning Phonology.
3. Teaching-learning Morphology.
4. Teaching-learning Spelling.
5. Teaching-learning Grammatical concepts.
6. Teaching-learning Speaking.

\section{b. Practices that are indirectly related to skills, sub-skills and components of (L2).}

1. Checking comprehension.

2. Assessment of comprehension.

3. Evaluation through (L1)- translation.

4. Checking understanding of very complex expressions, like idioms, phrases, etc.

5. Testing.

6. language analysis.

7. Explanation of errors.

8. Providing feedback.

9. Giving assignments.

10. Introducing the major differences between the $(L 1)$ and the (L2).

11. Eliciting the meanings of words and sentences.
1. Saving classroom time .

2. Giving instructions.

3. Negotiation of the syllabus and the lesson.

4. Record keeping.

5. Classroom management.

6. Organizing the class and tasks.

7. Scene setting; setting the activity objective.

8. Discussion of cross-cultural issues.

9. Building rapport between the teacher and the leaner .

10. Creating a friendly classroom atmosphere.

11. Creating a more relaxed classroom environment.

12. Socializing in the classroom.

13. Saving a lot of guessing.

14. Reducing students' anxiety.

15. Building motivation, focus their attention resources.

16. Personal comments.

17. Exam announcements.

18. Humor.

19. Elicitation of student contributions.

20. Taking students' attendance. 
In regard to the second question of this study, It should also be added that very few studies of the available related literature dealt with the vehicle technique which is normally enhanced in order to apply this applicability scope of (L1); this study, and in reference to the surveyed literature, directly focused the attention on (L1)-translation as the vehicle technique that is used in order to carry out the applicability scope of (L1) in the teaching- learning of the skills, sub-skills, and components of (L2). As a result, and parallel with the findings and conclusions of this study, it can be stated that (L1)-translation to (L2) items, components, patterns, skills, and sub-skills is a central and, to some extent, a sole (L1)-related technique which facilitates, to a maximum degree, the applicability scope not only in the teaching-learning process, but also as a means of assessment and testing of (L2) competency and achievement .

\section{Findings and conclusions}

The sole aim of this study was to investigate the applicability scope of (L1) in the teaching-learning of the skills, sub-skills, and components of (L2), which is mostly English as considered by the available related literature, and, by the same token, to investigate the vehicle technique through which such an applicability scope of (L1) is carried out for the purpose of teaching learning the skills, sub-skills, and components of (L2).

Findings of this study indicate that the applicability scope of (L1) can be categorized into three main domains: The first one includes those applications that are directly connected with the teaching - learning of the skills, sub-skills and components of (L2); the second includes a category of those applications that are indirectly related to the teaching - learning of the skills, sub-skills and components of (L2); while the third includes a category of applications that are barely and remotely related to the teaching-learning of the skills, sub-skills and components of (L2). As a result, this study came to the conclusion that those skills, sub-skills and components of (L2), which can be taught or learnt within such an applicability scope of (L1), are surprisingly very limited and not as wide as they thought to be because they constitute only (6) out of the sum of (37) other applications of this applicability scope. Findings of this study indicate that (11) applications of the applicability scope of (L1) are indirectly related to the teaching-learning of the skills, sub-skills and components of (L2), while the sum of (20) other applications are barely and remotely related to the teaching-learning of the skills, sub-skills and components of (L2). Accordingly, this study concludes that the applicability scope of (L1) is mostly enhanced and oriented towards establishing conditions that are professedly supposed to facilitate the process of the teaching-learning of (L2), rather than the teaching-learning of the skills, sub-skills, and components of (L2). Findings of this study also indicate that (L1)-translation technique is mostly employed as a vehicle and a method to carry out those practices categorized within the applicability scope of (L1) in the teaching- learning of the skills, sub-skills and components of (L2); in this regard this study came up with the conclusion that (L1)- translation is seemingly a lone and an overly the most common vehicle technique that is enhanced to thoroughly implement all the applications within the applicability scope of (L1) classified by this study; in this regard, findings of this study indicated that (L1)translation is commonly used as a method of assessment and testing to evaluate students or learners' achievement and competency in (L2)- which is mostly English as mentioned above. Findings of this study indicate an absence of an applicability scope of (L1) in regard to the teaching-learning of the writing skills of (L2). In the absence of any defined, categorized, and tabulated applicability scope of (L1), findings of this study also indicate the existence of problems, restrictions, and risky outcomes that are directly or indirectly connected with the use of (L1) in the teaching-learning of (L2) such as the possibility of damaging the amount and originality of the (L2) output and exposure, the state of contradiction between what teachers actually do inside classrooms and their real attitudes towards (L1) usage, the transfer of patterns and structures of (L1) into (L2) in a distorting way, and the concentration on creating a calm classroom and a learning environment that goes with students and learners' favorites rather than the teaching -learning of the skills, sub-skills, and components of (L2).

\section{Recommendations}

Based on the findings and conclusions of this study, this study recommends carrying out more research to investigate the applicability scope of (L1) in the teaching and learning of the writing skills of English as (L2). Also, the researcher recommends that further empirical studies are needed to investigate whether students or learners of (L2) follow nearly the same tactics and techniques they had been following when they acquired their native (L1). As far as the categorized applicability scope in this study is concerned, the researcher recommends more empirical research to investigate the impact of carrying out applicability scope of the native (L1) on students and learners' achievement in the skills, sub-skills, and components of English as (L2). This study also recommends that more research is highly advised to investigate the effectiveness (L1)-translation as a vehicle and as a central technique to carry out the applicability scope of (L1) in the teaching -learning of the skills, sub-skills, and components of (L2), and its reliability as an assessment or testing method to evaluate (L2) competency level. This study finally recommends that those would-be teachers should be trained on how to better exploit the applicability scope of (L1) in a defined, categorized, and constructive way. 


\section{About the Author}

Abd-AL-Hameed Mustafa Mahmoud Jabsheh, Lecturer, Department of Languages, Palestine Technical University- Kadoorie (PTUK) \Tulkarm Campus- Palestine. The author has been working as a teacher and lecturer of English Language since 1999; has published some research on English language teaching, linguistics, and literature.

\section{References}

[1] Al-Buraiki, M. A. (2008). The L1 in young learner classrooms: Teachers' views and practices. Retrieved June, 19, 2010.

[2] Al-Jadidi, H. S. S. (2009). Teaching English as a foreign language in Oman: An exploration of English language teaching pedagogy in tertiary education [Doctoral dissertation, Victoria University].

[3] Alrabah, S., Wu, S. H., Alotaibi, A. M., \&Aldaihani, H. A. (2016).English Teachers' Use of Learners' L1 (Arabic) in College Classrooms in Kuwait. English Language Teaching, 9(1), 1-11.

[4] Atkinson, D. (1987). The mother tongue in the classroom: A neglected resource?. ELT journal, 41(4), 241-247.

[5] Atkinson, D. (1993). Teaching monolingual classes (Vol. 12). London: Longman.

[6] Auerbach, E. R. (1993). Reexamining English only in the ESL classroom. TESOL quarterly, 27(1), 9-32.

[7] Ausubel, D. G. (1963).Cognitive structure and the facilitation of meaningful verbal learning1. Journal of teacher education, 14(2), 217-222.

[8] Brooks, F. B., \&Donato, R. (1994). Vygotskyan approaches to understanding foreign language learner discourse during communicative tasks. Hispania, 262-274.

[9] Butzkamm, W. (2003). We only learn language once. The role of the mother tongue in FL classrooms: death of a dogma. Language learning journal, 28(1), 29-39.

[10] Cameron, L. (2001). Teaching languages to young learners. Ernst KlettSprachen.

[11] Canagarajah, A. S. (1995). Functions of codeswitching in ESL classrooms: Socialising bilingualism in Jaffna. Journal of multilingual \& multicultural development, 16(3), 173-195.

[12] Cole, S. (1998). The use of L1 in communicative English classrooms. LANGUAGE TEACHER-KYOTO-JALT-, 22, 11-14.

[13] Cook, V. (2001). Using the first language in the classroom. Canadian modern language review, 57(3), 402-423.

[14] Cook, V. (2013). Second language learning and language teaching. Routledge.

[15] Copland, F., \&Neokleous, G. (2011). L1 to teach L2: Complexities and contradictions. ELT journal, 65(3), 270-280.

[16] Dailey-O'Cain, J., \&Liebscher, G. (2009). Teacher and student use of the first language in foreign language classroom interaction: Functions and applications. First language use in second and foreign language learning, 131-144.

[17] Debreli, E. (2016). Perceptions of Non-Native EFL Teachers' on L1 Use in L2 Classrooms: Implications for Language Program Development. English Language Teaching, 9(3), 24-32.

[18] De la Campa, J. C., \&Nassaji, H. (2009). The amount, purpose, and reasons for using L1 in L2 classrooms. Foreign language annals, 42(4), 742-759.

[19] Farrah, M., \& Salah, N. (2012). Examining the use of Arabic in English classes at the primary stage in Hebron government schools, Palestine: Teachers' perspective.

[20] Fine, J. (1988). The place of discourse in second language study. Research. Norwood NJ: Ablex, 1-16.

[21] Ghobadi, M., \&Ghasemi, H. (2015). Promises and Obstacles of L1 Use in Language Classrooms: A State-of-the-Art Review. English Language Teaching, 8(11), 245-254.

[22] Giles, H., \&Ogay, T. (2006). Communication accommodation theory. In B. B. Whaley, \& W. Samter (Eds.), Explaining communication: Contemporary theories and exemplars (pp. 293-310). Mahwah, NJ: Erlbaum

[23] Gomathi, B., \&Kiruthika, P. (2013). Role of L1 in English language teaching to rural area students with reference to erode region. International Journal of Humanities and Social Science Invention, 2(12), 24-26.

[24] Gulzar, M. A. (2010). Code-switching: Awareness about its utility in bilingual classrooms. Bulletin of Education and Research, 32(2), 23-44.

[25] Harbord, J. (1992). The use of the mother tongue in the classroom. ELT journal, 46(4), 350-355.

[26] Harmer, J. (2007). The practice of English language teaching. Harlow: Pearson Longman.

[27] James, J. (1977). Language transfer reconsidered. Interlanguage studies bulletin, 2(3), 7-21.

[28] Kayaoğlu, M. N. (2012). The use of mother tongue in foreign language teaching from teachers" practice and perspective. PamukkaleÜniversitesiEğitimFakültesiDergisi, 32(2), 25-35.

[29] Kim, Y., \&Petraki, E. (2009). Students' and teachers' use of and attitudes to L1 in the EFL classroom. Asian EFL Journal, 11(4), 58-89.

[30] Knight, T. (1996). Learn vocabulary through a shared speaking task. LANGUAGE TEACHER-KYOTO-JALT-, 20, 24-34.

[31] Liebscher, G., \& DAILEY-O'CAIN, J. E. N. N. I. F. E. R. (2005).Learner code-switching in the content-based foreign language classroom. The Modern Language Journal, 89(2), 234-247.

[32] Atkins, B. T., \&Varantola, K. (1997).Monitoring dictionary use. International Journal of Lexicography, 10(1), 1-45.

[33] Mahmoudi, L., \&Amirkhiz, S. Y. Y. (2011).The Use of Persian in the EFL Classroom--The Case of English Teaching and Learning at PreUniversity Level in Iran. English Language Teaching, 4(1), 135-140.

[34] Mart, Ç. T. (2013).The facilitating role of L1 in ESL classes. International Journal of Academic Research in Business and Social Sciences, 3(1), 9.

[35] McKeown, M. G. (1993).Creating effective definitions for young word learners. Reading Research Quarterly, 17-31.

[36] Meyer, H. (2008). The pedagogical implications of L1 use in the L2 classroom.

[37] Nation, P. (2003). The role of the first language in foreign language learning. Asian EFL journal, 5(2), 1-8.

[38] Phillipson, R. (2012). Linguistic imperialism. The Encyclopedia of applied linguistics, 1-7.

[39] Rabbidge, M. (2014). Exploring Non--native English Speaker Teachers Classroom Language Use in South Korean Elementary Schools. TeslEj, 17(4). 
[40] Ringbom, H. (1983). On the Distinctions of Item Learning vs. System Learning and Receptive Competence vs. Productive Competence in Relation to the Role of L1 in Foreign Language Learning.

[41] Rolin-lanziti, J., \&Brownlie, S. (2002). Teacher use of learners' native language in the foreign language classroom. Canadian Modern Language Review, 58(3), 402-426.

[42] Ross, N. J. (2000). Interference and intervention: Using translation in the EFL classroom. Modern English Teacher, 9(3), 61-66.

[43] Sampson, A. (2012). Learner code-switching versus English only. ELT journal, 66(3), 293-303.

[44] SchweersJr, C. W. (1999, April). Using L1 in the L2 classroom. In English teaching forum (Vol. 37, No. 2, pp. 6-9).

[45] Sevim, I. N. A. L., \&Turhanli, I. (2019).Teachers' opinions on the use of L1 in EFL classes. DilveDilbilimiÇalışmalarıDergisi, 15(3), 861-875.

[46] Sharma, K. (2006). Mother tongue use in English classroom. Journal of NELTA, 11(1-2), 80-87.

[47] Tang, J. (2002, January). Using L1 in the English classroom.In English teaching forum (Vol. 40, No. 1, pp. 36-43).

[48] Taki, S., Soghady, N., \& Reza, M. (2013).The Role of L1 in L2 Idiom Comprehension. Journal of Language Teaching \& Research, 4(4).

[49] Turnbull, M., \& Arnett, K. (2002). 11. TEACHERS'USES OF THE TARGET AND FIRST LANGUAGES IN SECOND AND FOREIGN LANGUAGE CLASSROOMS. Annual review of applied linguistics, 22, 204.

[50] Weschler, R. (1997). Uses of Japanese (L1) in English Classroom: Introducing the Functional-Translation Method, The Internet TESL Journal,[On-line] 3 (2).

[51] Wolter, B. (2001). Comparing the L1 and L2 mental lexicon: A depth of individual word knowledge model. Studies in second language acquisition, 23(1), 41-69.

[52] Yang, S. S. (2010).The Influence of Schema and Cultural Difference on L1 and L2 Reading. English Language Teaching, 3(4), $175-180$. 